\title{
Position Servo Motor PI Control System by Using DSP
}

\author{
Zhang Jianjun \\ School of Physics and Information Engineering, \\ Jianghan University, \\ Wuhan 430056, P.R. China \\ E-mail:jianj_zhang@126.com
}

\begin{abstract}
In this paper, we study the position servo control system controlled by DSP. The control algorithm implemented in our application is PI. PWM signals is used to share the switching dissipation ePWM module of the DSP and achieved twice switching frequency. A numerical consideration and the software flow charts are given. At last, the simulation results show the effectiveness of the proposed method.
\end{abstract}

Keywords- position servo control; PI; simulation;PWM; controller

\section{INTRODUCTION}

The study of stability and stabilization for position servo control systems has received considerable attention. [1] presented the design and experimental evaluation of a position controller for an hydraulic actuator where the only available measure is the actuator's position. [2]combined velocity and position controllers with 2 order system, simulation was performed after current controllers were composed, which were able for current loop to work ideally. A new low-cost integrated position feedback unit, which was composed of the integrated position sensor, signal processing hardware and software, are described in[3]. [4]described the basic principles of stripe deviation electrohydraulic position servo control system and carries out analysis, modeling and MATLAB/Simulink simulation according to design requirement. Based on a two-port network model and linear friction model, the general mathematical model of electro-hydraulic servo position control system including pipeline effect was established[5]. A continuous sliding mode controller (SMC) was developed to deal with the problem of position synchronization for dual spindle servo systems and synchronization error was defined as the differential position error between the two servo systems that follow same reference motion command[6].

In this paper, a very low cost two-axis position servo system is developed. The motor we use is PMDCM which has been in mass production for HP printer application. More importantly, an optical encoder with two-channel 500 counts per motor revolution has already been integrated on terminal of the motor, which make us more convenient to setup the system. Since we have not found any real application at this moment, all the parameters we select are just based on the characteristic of the motor in order to let the motor run with capable ability. From performance curve (data) we notice that the output torque is about 293.2 $\mathrm{m}-\mathrm{Nm}$ with $2568 \mathrm{rpm}$ speed and 5.37Amp load current at maximum power $(78.9 \mathrm{~W})$. So, we define the maximum load current is $5 \mathrm{Amp}$, and running speed is about $2500 \mathrm{rpm}$ for the speed loop control.

This paper is organized as follows. In section 2, hardware design is presented. In section 3, software design is presented and the software flow is discussed. A numerical example is presented in section 4 to illustrate the theoretical results, and the conclusions are drawn in section 5 .

\section{HARDWARE DESIGN}

In this correspondence, we use the DSP to control the motor. The hardware block is shown in Fig.1.

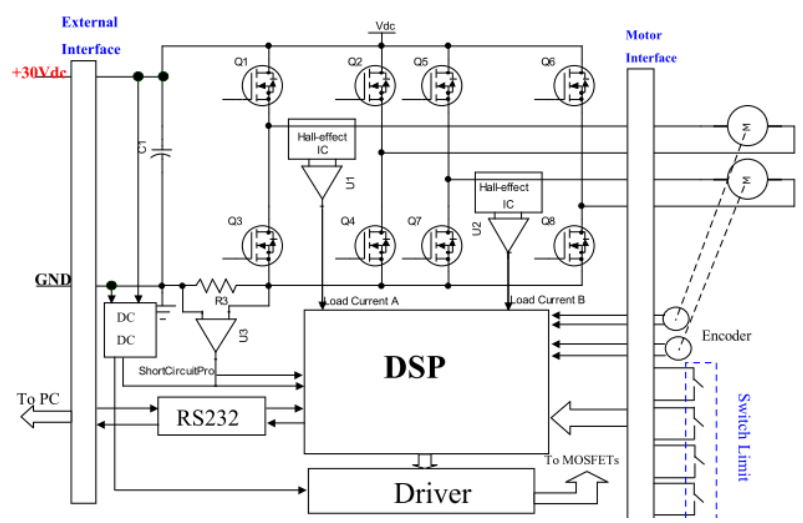

Fig.1 Hardware Block

\section{A. . Current feedback}

The current inner loop requires phase current of the DC servomotor as input. In our application, hall effect-based linear current sensor ACS704ELC-005 is employed as shown in Fig.2.Notes that the sensor has $133 \mathrm{mV} / \mathrm{A}$ output sensitivity and $15 \mathrm{~A}$ dynamic range.

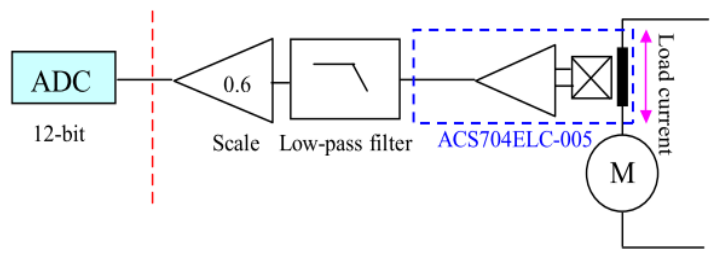

Fig.2 Sensed Current 


\section{B. Speed/Position feedback}

In this DC servo drive a 500 pulse incremental encoder produces the rotor speed. The two sensor output channels (A and B) are wired directly to the eQEP unit of the DSP Controller, which counts both edges of the pulses.

\section{Driver}

We apply PWM signals on both sides in order to share the switching dissipation. ePWM module of the DSP will work in up-down mode, and twice switching frequency will be achieved on motor side.

\section{SOFTWARE DESIGN}

\section{A. PID Algorithm}

The control algorithm implemented in our application is PI.

$$
u(t)=K_{p} e(t)+K_{i} \int d t
$$

For the rectangular approximation, the final form of PI is shown as below:

$$
u(t)=K_{p} e_{k}+K_{i} \sum_{j=0}^{k} e_{j} T
$$

We separate (2) into two parts. One is proportional controller, the other one is integral controller.

For P controller: $u_{k_{-} P}=K_{p} e_{k}$

For I controller: $u_{k_{-} I}=u_{k-1}+K_{i} T e_{k}$

So, we can get

$$
u_{k_{-} P I}=u_{k_{-} P}+u_{k_{-} I}=u_{k_{-1}}+K_{p} e_{k}+K_{i} T e_{k}
$$

The traditional PI algorithm is shown as follow:

$$
u_{k}=u_{k-1}+K_{p}\left(e_{k}-e_{k-1}\right)+K_{i} T e_{k}
$$

Compared (3) with (4), (3) is more reliable especially when $\mathrm{Ki}$ is very small or Ki equal zero.

\section{B. Software Organization}

This software is based on two modules: the initialization module shown in Fig.3 and the run module shown in Fig.4.The former is performed only once at the beginning. The second module is based on a waiting loop interrupted by the PWM underflow. When the interrupt flag is set, this is acknowledged and the corresponding Interrupt Service Routine (ISR) is served. The inner loop for current regulation is computed within the PWM ISR and thus runs at the same frequency as the period frequency. The outer loop for speed and position regulations are computed every 50th PWM periods.

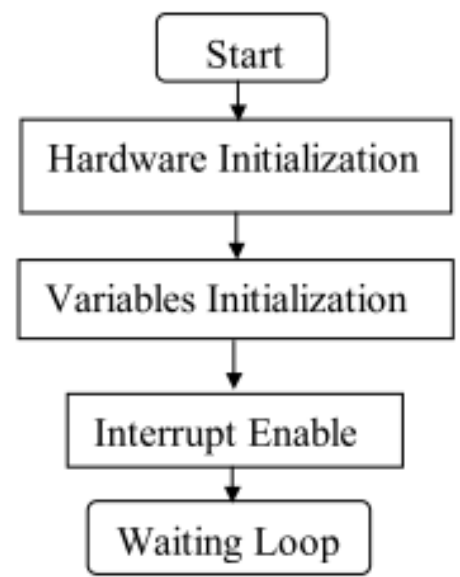

Fig.3 Initialization Module

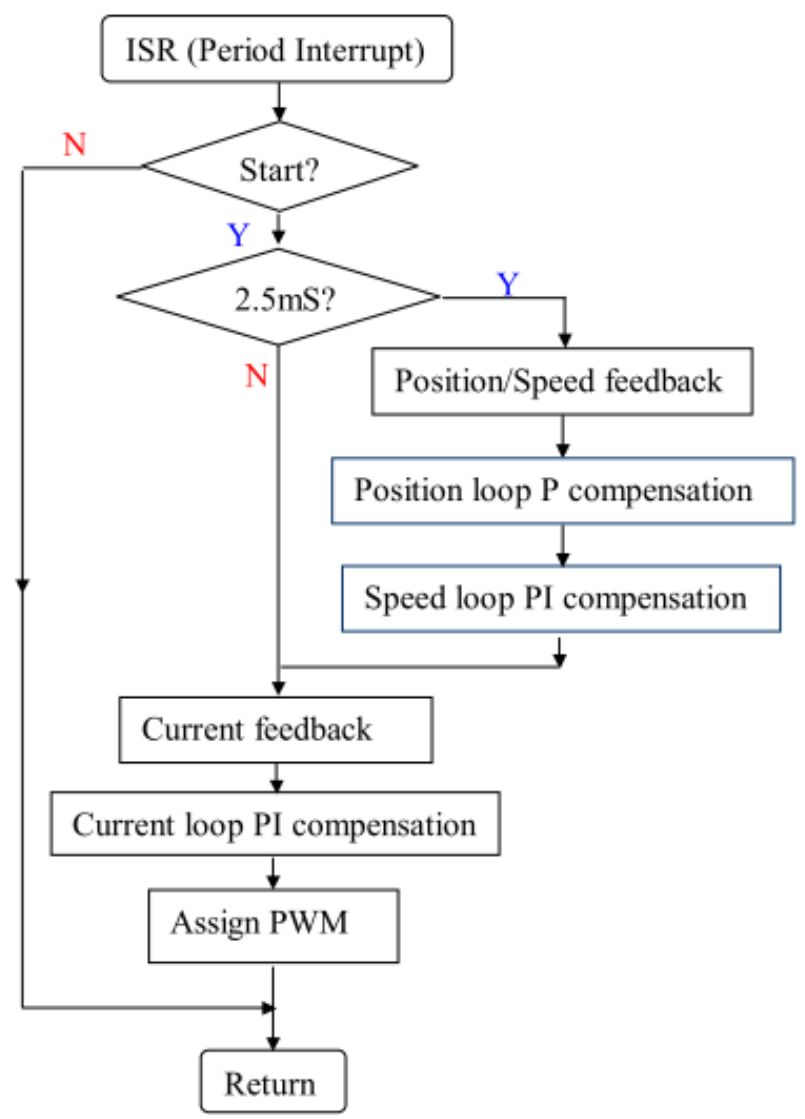

Fig.4 Run Module

\section{A NUMERICAL EXAMPLE}

To illustrate the method proposed in this contribution, a numerical example is given in the following. To avoid complex mathematical calculation, PU model is used here. So that the software representation of speed, current is equal 
to one when the drive has reached its base value under base voltage and base load.

The following parameters are used in our application:

$$
\begin{aligned}
& \text { Motor: } \mathrm{Ra}=3 \Omega ; \\
& \mathrm{La}=5.6 \mathrm{mH} ; \mathrm{J}=0.00007 \mathrm{~kg} . \mathrm{m}^{\wedge} 2 / \mathrm{s}^{\wedge} 2 ; \mathrm{B}=0 \mathrm{Nms} .
\end{aligned}
$$

Base values: $\mathrm{Ua}=30 \mathrm{~V}$ $\mathrm{Ia}=4.7 \mathrm{~A} ; \mathrm{Na}=2500 \mathrm{rpm} ; \mathrm{Pa}=0.1$ Turns.

Current Loop: Kp2=10; Ki2=800; Imax=+/-5A

Speed Loop: Kp1=2.5; Ki1=10. Speed $\max =+/-$ 2500rpm

Position Loop: $\mathrm{Kp} 0=0.4$.

Where:

Electric resistance( $\mathrm{Ra})$;

Electric inductance (La);

Damping ratio of the mechanical system (B);

Electromotive force constant $(\mathrm{K}=\mathrm{Ke}=\mathrm{Kt})$;

Moment of inertia of the rotor $(\mathrm{J})$;

Base Voltage ( Ua );

Base Current ( Ia );

Base Speed ( $\mathrm{Na}$ ).

Every moving body possesses inertia around rotating axis. For leadscrew application, the total inertia includes motor inertia, load inertia, leadscrew inertia and the coupler inertia. To avoid the over-complex stability analysis due to different inertia for different application, here we just give the analysis results in the condition that the motor runs without any mechanical connection. This means we just analysis the effect of motor inertia to the whole system. For the real application, the analysis process is the same. The bode diagrams are as flows:

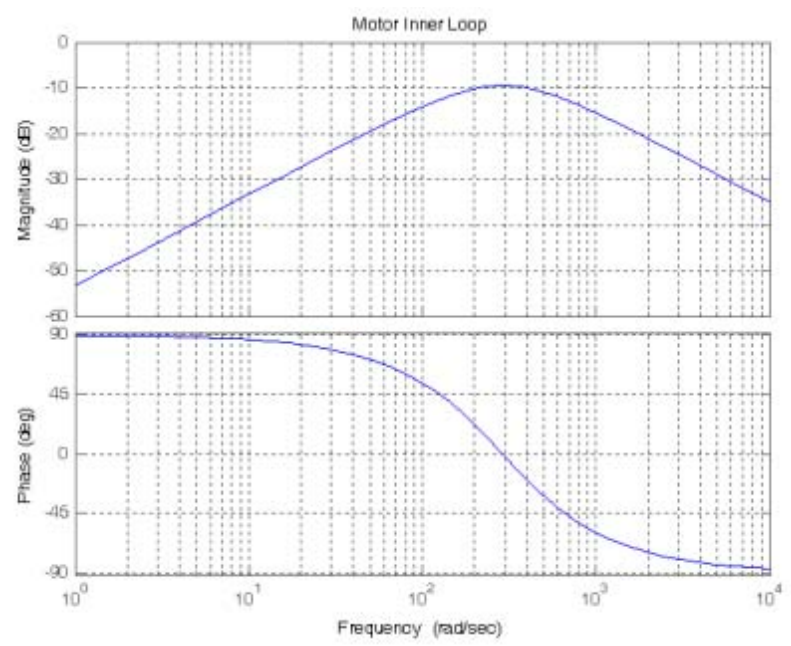

Fig.5 Inner Loop

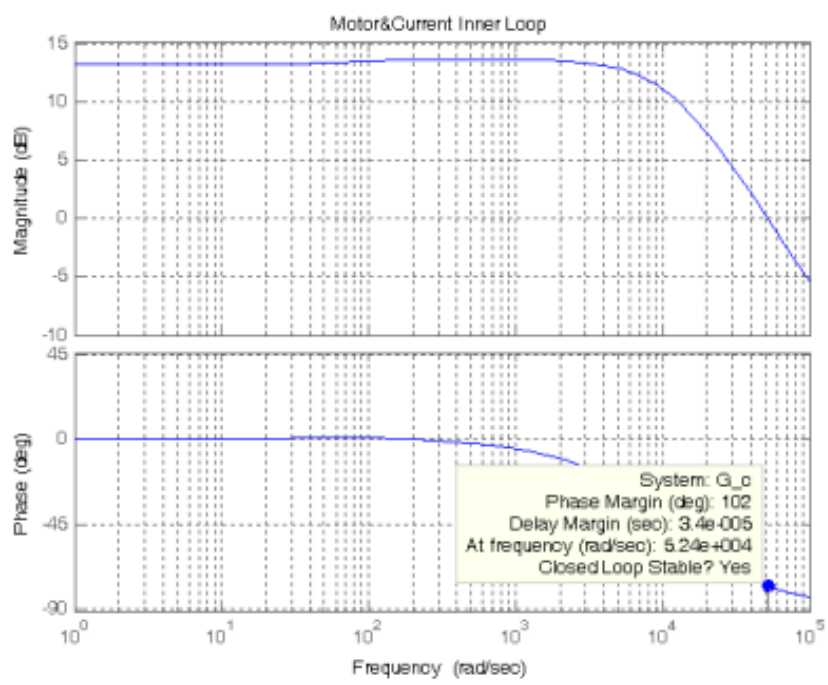

Fig.6 Current Loop

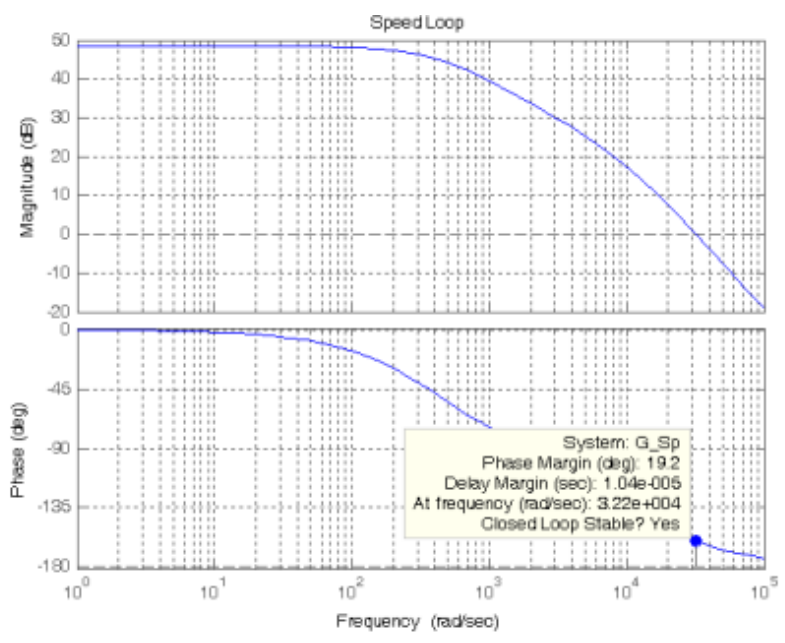

Fig.7 Speed Loop

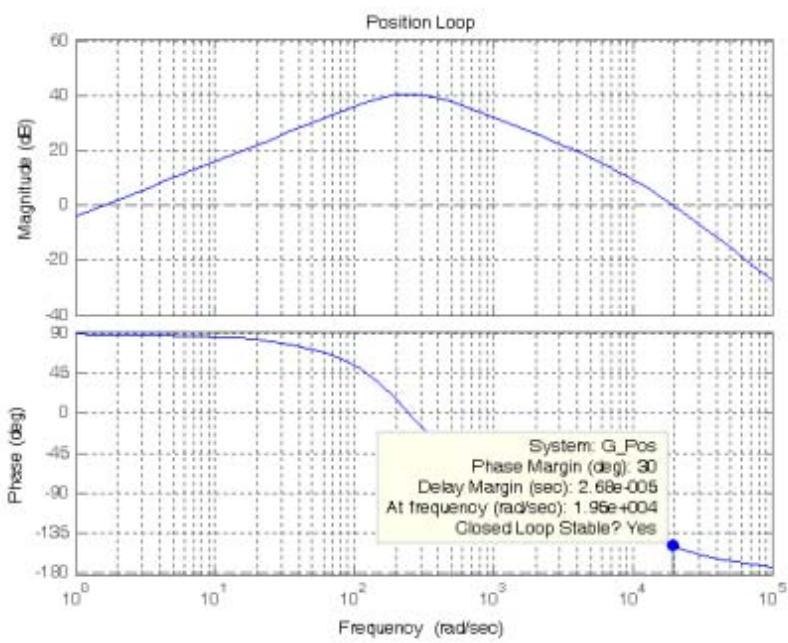

Fig.8 Position Loop 
From the bode diagrams, we can see that each loop is very stable. For the position loop, it has $30^{\circ}$ phase margin with $20,000 \mathrm{rad} / \mathrm{sec}$ bandwidth.

\section{CONCLUSIONS}

In this correspondence, we studied the position servo control system controlled by DSP. A new PI control algorithm is proposed for the system. The numerical example simulation results demonstrate that the method is effective.

\section{ACKNOWLEDGMENT}

This work was supported by the Science and Technology Research of Keystone Projects of Educational Commission of Hubei Province (D20123405), the Research Project of Educational Commission of Wuhan City(2011055) and the Science and Technology Research of Construction Commission of Hubei Province (2012)78.

\section{REFERENCES}

[1] F, Basile, P , Chiacchio , "Implementation of hydraulic servo controllers with only position measure" [J]. International Journal of Robotics and Automation, v 24, n 1, p 20-37, 2009.

[2] Ki-Woo.Park, Ki-Woo,"A study on current, velocity, position gain tuning technique of servo position controller using simulation" [J]. Journal of Institute of Control, Robotics and Systems, v 17, n 7, p 634-640, 2011.

[3] Jing-zhuo . Shi, Huimin . Zhang, Xun.Liu, "Novel integrated position measurement unit for stepping motor servo control" [J].Measurement: Journal of the International Measurement Confederation, v 44, n 1, p 80-87, 2011.

[4] Li-guo .Wang," Analysis and simulation of strip deviation electrohydraulic position servo control system", 2011 International Conference on Electronics, Communications and Control, p 1878$1881,2011$.

[5] Chun-fang. Dong, Juan. Lu, Qing-xin. Meng," Position control of an electro-hydraulic servo system based on improved Smith predictor", Proceedings of 2011 International Conference on Electronic and Mechanical Engineering and Information Technology, EMEIT 2011, v 6, p 2818-2821, 2011.

[6] Burak. Sencer, Tatsuya. Mori, Eiji. Shamoto," A sliding mode controller design for position synchronization of dual spindle servo systems", 5th CIRP Conference on High Performance Cutting 2012, v 1, n 1, p 250-254, 2012. 